\title{
Cardiac steatosis and left ventricular remodeling in heart failure with reduced and preserved ejection fraction
}

\author{
Masliza Mahmod ${ }^{1 *}$, Nikhil Pal ${ }^{1}$, Cameron Holloway ${ }^{1}$, Vanessa M Ferreira', Sairia Dass ${ }^{1}$, Jane M Francis ${ }^{1}$, \\ Oliver Rider ${ }^{1}$, Theodoros D Karamitsos ${ }^{1,2}$, Houman Ashrafian', Stefan Neubauer ${ }^{1}$
}

From 18th Annual SCMR Scientific Sessions

Nice, France. 4-7 February 2015

\section{Background}

Heart failure (HF) is characterised by alterations in fatty acid and glucose metabolism. We aimed to determine if myocardial lipid is increased in HF with reduced (HFrEF) and preserved (HFpEF) ejection fraction (EF), and assess whether it is related to cardiac structure and function.

\section{Methods}

25 HFrEF due to dilated cardiomyopathy (DCM), 18 HFpEF (defined by EF $>50 \%$, abnormal diastolic function, maximum oxygen consumption $<80 \%$ predicted for age, height and gender, with a cardiac limitation in exercise) and 28 normal volunteers were prospectively recruited. All subjects underwent cardiovascular magnetic (MR) resonance at $3 \mathrm{~T}$ for the determination of left ventricular (LV) volumes and function, and cardiac ${ }^{1} \mathrm{H}$ MR spectroscopy to quantify myocardial lipid/water (\%).

\section{Results}

As expected DCM patients had significantly increased LV volumes and reduced EF, whilst HFpEF patients had significantly increased LV mass to end-diastolic volume ratio (LV mass/EDV). Importantly, cardiac lipid was

Table 1 Clinical characteristics of patients with reduced (HFrEF), preserved (HFpEF) ejection fraction and normal controls.

\begin{tabular}{|c|c|c|c|c|}
\hline & HFrEF $(n=25)$ & HFpEF $(n=18)$ & Normals $(n=28)$ & $P$ value \\
\hline Age (years) & $60 \pm 11^{*}$ & $74 \pm 6^{* *}$ & $61 \pm 5$ & $<0.001$ \\
\hline Female, n (\%) & $8(32)$ & $12(67)$ & $12(43)$ & 0.075 \\
\hline \multicolumn{5}{|l|}{ NYHA class, n (\%) } \\
\hline 1 & $3(12)$ & 0 & 0 & - \\
\hline$\|$ & $21(84)$ & $18(100)$ & 0 & - \\
\hline III & $1(4)$ & 0 & 0 & - \\
\hline Body mass index $(\mathrm{kg} / \mathrm{m} 2)$ & $28 \pm 5$ & $28 \pm 6$ & $27 \pm 4$ & 0.29 \\
\hline$E^{\prime}$ & - & $4.5 \pm 1.2$ & $13.1 \pm 3.5$ & 0.001 \\
\hline E/E' ratio & - & $10.7 \pm 2.7$ & $7.6 \pm 3.0$ & 0.002 \\
\hline E/A ratio & - & $0.7 \pm 0.26$ & $1.0 \pm 0.3$ & 0.001 \\
\hline Blood glucose & $5.4 \pm 1.0$ & $5.5 \pm 1.1$ & $5.2 \pm 1.0$ & 0.55 \\
\hline Free fatty acids & $0.44 \pm 0.22$ & $0.49 \pm 0.29$ & $0.54 \pm 0.30$ & 0.46 \\
\hline
\end{tabular}

\footnotetext{
'Division of Cardivascular Medicine, Radcliffe Department of Medicine,
} Oxford Centre for Clinical Magnetic Resonance Research, Oxford, UK 
Table 1 Clinical characteristics of patients with reduced (HFrEF), preserved (HFpEF) ejection fraction and normal controls. (Continued)

\begin{tabular}{|c|c|c|c|c|}
\hline Triglycerides (mmol/L) & $1.5 \pm 0.7$ & $1.2 \pm 0.4$ & $1.1 \pm 0.3$ & 0.12 \\
\hline Low-density lipoprotein (mmol/L) & $2.9 \pm 0.9$ & $2.4 \pm 0.7$ & $3.1 \pm 1.1$ & 0.07 \\
\hline High-density lipoprotein (mmol/L) & $1.4 \pm 0.5$ & $1.6 \pm 0.4$ & $1.4 \pm 0.4$ & 0.49 \\
\hline \multicolumn{5}{|l|}{ CMR findings } \\
\hline Cardiac lipid/water (\%) & $0.67 \pm 0.42 \dagger$ & $1.06 \pm 0.83^{* *}$ & $0.44 \pm 0.17$ & 0.001 \\
\hline LV end-diastolic volume (ml) & $233 \pm 82 \dagger$ & $111 \pm 21 \neq$ & $144 \pm 28$ & $<0.001$ \\
\hline LV ejection fraction (\%) & $38 \pm 9+$ & $74 \pm 6 \neq$ & $69 \pm 5$ & $<0.001$ \\
\hline LV mass index (g/m2) & $80 \pm 25 \dagger$ & $54 \pm 12 \ddagger$ & $55 \pm 11$ & $<0.001$ \\
\hline LV mass/EDV (g/mL) & $0.69 \pm 0.18^{*}$ & $0.91 \pm 0.22^{* *}$ & $0.74 \pm 0.16$ & 0.003 \\
\hline
\end{tabular}

${ }^{*} p<0.05$ vs HFpEF and $p>0.05$ vs normal; ** $p<0.05$ vs normal.

$+p<0.05$ vs HFpEF and normal; $\chi \neq p>0.05$ vs normal.

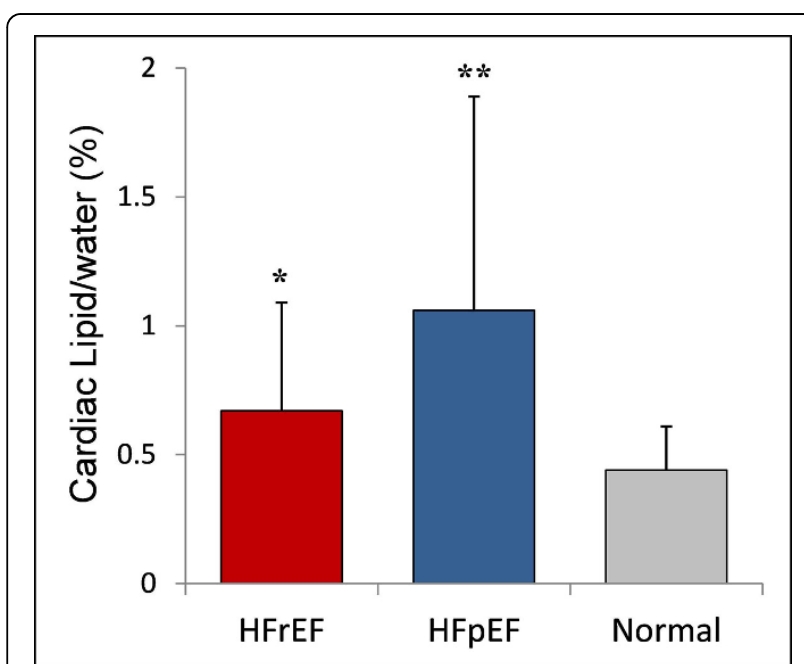

Figure 1 Cardiac lipid content in HFrEF, HFpEF and normal subjects. ${ }^{*} p<0.05$ vs HFpEF and normal; ${ }^{* *} p<0.05$ vs normal.

increased in both HFrEF and HFpEF when compared to normal controls (cardiac lipid/water $0.67 \pm 0.42 \%$ in HFrEF; $1.06 \pm 0.83 \%$ in HFpEF versus normal controls $0.44 \pm 0.17$, all $\mathrm{p}<0.05$ ), with HFpEF group having the highest level of cardiac lipid (Table 1, Figure 1). In DCM patients, cardiac lipid negatively correlated with $\operatorname{LVEF}(\mathrm{r}=-0.33, \mathrm{p}=0.03)$ and positively correlated with LV size $(r=0.54, p<0.001)$. In HFpEF, cardiac lipid positively correlated with age $(\mathrm{r}=0.41, \mathrm{p}=0.008)$ and $\mathrm{LV}$ mass/EDV ( $\mathrm{r}=0.37, \mathrm{p}=0.02)$. Although HFpEF patients were significantly older, with age positively correlated with cardiac lipid, multiple regression analysis showed that age is not an independent predictor of cardiac lipid.

\section{Conclusions}

This is the first study to demonstrate that myocardial steatosis occurs in both HFrEF and HFpEF and is related to parameters of LV remodeling. This suggests that myocardial lipid may play a role in the pathophysiological processes of LV remodeling in both HFrEF and HFpEF. Cardiac lipid accumulation may be a potential therapeutic target in these conditions.

\section{Funding}

N/A.

\section{Authors' details}

'Division of Cardivascular Medicine, Radcliffe Department of Medicine, Oxford Centre for Clinical Magnetic Resonance Research, Oxford, UK. ${ }^{2} 1$ st Department of Cardiology, AHEPA Hospital, Aristotle University of Thessaloniki, Thessaloniki, 54636, Greece.

Published: 3 February 2015

doi:10.1186/1532-429X-17-S1-P309

Cite this article as: Mahmod et al:: Cardiac steatosis and left ventricular remodeling in heart failure with reduced and preserved ejection fraction. Journal of Cardiovascular Magnetic Resonance 2015 17(Suppl 1): P309.

Submit your next manuscript to BioMed Central and take full advantage of:

- Convenient online submission

- Thorough peer review

- No space constraints or color figure charges

- Immediate publication on acceptance

- Inclusion in PubMed, CAS, Scopus and Google Scholar

- Research which is freely available for redistribution

Submit your manuscript at www.biomedcentral.com/submit
() Biomed Central 